\title{
PEMANFAATAN SOCIAL NETWORK ANALYSIS (SNA) UNTUK MENGANALISIS KOLABORASI KARYAWAN PADA PT. ARUM MANDIRI GROUP
}

\author{
Dendy Kurniawan ${ }^{1}$, Ade iriani ${ }^{2}$, Danny Manongga ${ }^{3}$ \\ ${ }^{1}$ Magister Sistem Informasi, Fakultas Teknologi Informasi, Universitas Kristen Satya Wacana \\ Salatiga, Indonesia, e-mail: dendy.kurnia94@gmail.com \\ ${ }^{2}$ Magister Sistem Informasi, Fakultas Teknologi Informasi, Universitas Kristen Satya Wacana \\ Salatiga, Indonesia, e-mail: ade.iriani@uksw.edu \\ ${ }^{3}$ Magister Sistem Informasi, Fakultas Teknologi Informasi, Universitas Kristen Satya Wacana \\ Salatiga, Indonesia, e-mail: danny.manongga@uksw.edu
}

\section{ARTICLE INFO}

Article history:

Received 10 October 2019

Received in revised form 14 October 2019

Accepted 2 January 2020

Available online 31 January 2020

\begin{abstract}
Industrial growth in Kendal, Central Java made PT. Arum Mandiri Group is trying to improve its business units by optimizing its human resources. One of the improvements in corporate HR is through collaborative communication between employees and leaders. This study aims to identify employee communication network collaboration in PT. Arum Group Mandiri has 3 divisions totaling 43 people by using the Social Network Analysis (SNA) method. The parameters used in this study include density, degree centrality, closeness centrality, and betweenness centrality. The result of this research are density level of $14.9 \%$ which is considered to have a weak bond because under $50 \%$. Individual number 31 has the highest of degree centrality with an outdegree value of 15 and indegree of 10 , while individual number 25 has the highest closeness centrality with value inCloseness 50.602 and outCloseness value 27.815. Individual number 25 also has the highest centrality betweenness with a value of Betweenness 743,194 and nBetweenness 43,159 . The results of this study are collaboration in the social network of each individual which is divided into three work divisions, namely the motorcycle repair division, the car / motorcycle washing division, and the housing division (property) and described in the form of a sociogram.
\end{abstract}

Keywords: colaboration, communication, SNA

\section{Pendahuluan}

Sebuah perusahaan dapat berkembang dengan baik apabila didukung kemampuan untuk bisa beradaptasi dengan perkembangan zaman. Perusahaan yang mampu menciptakan perubahanperubahan yang mengarah pada perbaikan akan menjadikan suasana kerja yang nyaman. Dalam 
mengelola sebuah perusahaan diperlukan keseimbangan sebagai syarat utama agar sumber daya manusia dapat berkembang secara produktif [1]. Manajemen perusahaan dituntut untuk dapat merumuskan konsep kebijakan dalam mengelola sumber daya manusia perusahaan agar bisa berkembang sesuai dengan kebutuhan perusahaan [1].

PT. Arum Mandiri Group merupakan salah satu perusahaan yang bergerak di bidang properti, jasa bengkel sepeda motor dan jasa cuci mobil - motor yang terletak di kabupaten Kendal Jawa Tengah. Selama ini dalam tata kelola organisasi sudah berjalan dengan baik, dimana sudah terdapat sruktur organisasi serta pembagian job description dan job specification antara beberapa karyawan. Dalam organisasi yang sudah memiliki struktur organisasi yang bagus biasanya secara komunikasi formal memiliki pola hubungan yang baik serta tidak ada kendala [2]. Kendala utama biasanya terjadi pada pola hubungan komunikasi informal, dimana komunikasi yang terjadi bukan karena hubungan profesional pekerjaan, sehingga diperlukan analisis terkait pola tersebut, khususnya kolaborasi antara para karyawan dari masing-masing divisi.

Kolaborasi merupakan salah satu metode dalam problem solving yang mengupayakan pencapaian tujuan bersama serta berbagi sumber daya (resources) yang ada, dimana dapat tercapai apabila dilakukan dengan tujuan meningkatnya etos kerja dan semakin baiknya hubungan kebersamaan antara anggota organisasi [3].

Komunikasi memiliki peran yang sangat sentral dalam sebuah perusahaan karena salah satu unsur komunikasi yaitu sumber informasi dapat mempengaruhi perilaku individu-individu dalam perusahaan [4], sehingga dapat mempengaruhi kinerja pegawai atau karyawan [5]. Dalam sebuah organisasi komunikasi akan berjalan lancar apabila didukung adanya jaringan informasi yang ada, diantaranya jaringan informal dan formal yang akan selalu ada serta digunakan dalam sebuah organisasi atau perusahaan, dimana salah satunya "The Piano Institute" di Surabaya [6].

Social Network Analysis (SNA) merupakan salah satu metode analisis dalam sebuah penelitian yang memiliki konsentrasi pada relationship reserach dan sering digunakan dalam mengukur sebuah hubungan dan menggambarkan beberapa informasi secara individu [7]. SNA juga dapat digunakan dalam pemetaan rekanan-rekanan pemerintah pada jaringan Sistem Pengadaan Secara Elektronik (SPSE) yang dapat dipelajari polanya sehingga dapat digunakan oleh pemerintah dalam menganalisis, mengevaluasi serta monitoring proses pengadaan lelang dalam SPSE [8]. Dengan adanya komunikasi yang lancar tanpa hambatan atau sekat, diharapkan terjadi kolaborasi yang baik antara karyawan di PT. Arum Mandiri Group, baik antar divisi maupun beda divisi serta diharapkan dapat terjadi sinergisitas proses kerja.

Dalam sebuah penelitian yang membahas topik analisis kolaborasi penelitian ilmiah dosen dengan menggunakan social network analysis (SNA) sebagai metode analisisnya, dimana hasilnya kolaborasi karya ilmiah yang diterbitkan baik skala nasional maupun internasional oleh dosen pada sebuah fakultas " $X$ " dilakukan pemetaan berdasarkan atribut program studi serta jabatan fungsional dosen (JAFA) menunjukkan adanya pola kolaborasi antara para aktor yang berdasarkan pengukuran dalam bentuk sociogram serta dalam bentuk sosiometri pada analisis masing-masing aktor [9].

Sebuah riset pada perguruan tinggi (Open University in Kupang) yang fokus pada kolaborasi mahasiswa yang bertujuan untuk memetakan interaksi sosial antar mahasiswa agar dapat memberikan dorongan memahami materi pembelajaran [10]. Hasil penelitian menunjukkan ada interaksi sosial pada mahasiswa di Open University tetapi nilainya sangat kecil [10]. Penelitian lainnya dilakukan pada perusahaan multifinance yang mengnalisis pemetaan jaringan komunikasi karyawan menggunakan social network analysis (SNA), dimana hasil penelitian terdapat hubungan dan interaksi sosial pada karyawan perusahaan multifinance baik komunikasi formal maupun komunikasi informal [2].

Berdasarkan beberapa referensi penelitian terdahulu yang membahas topik social network analysis (SNA) dalam sebuah organisasi, maka peneliti tertarik untuk menganalisis interaksi sosial yang terjadi pada karyawan PT. Arum Group Mandiri. Penelitian ini bertujuan untuk

TRANSFORMATIKA Vol.17, No.2, January 2020: $168-178$ 
mencari hubungan kolaborasi antara karyawan, dimana PT. Arum Group Mandiri memiliki 3 divisi (bengkel sepeda motor, cucian kendaraan bermotor dan perumahan/properti) yang memiliki keunikan dalam hal bidang usahanya tidak memiliki keterkaitan dengan bisnis utama. Hal ini yang menurut persepsi peneliti dapat menjadi penelitian yang memiliki nilai kebaharuan dan menjadi pembeda dengan penelitian-penelitian terdahulu.

\section{Metode Penelitian}

\section{a. Tahapan Pengumpulan Data}

Penelitian merupakan penelitian kualitatif deskriptif yang bertujuan untuk menganalisis kolaborasi karyawan di PT. Arum Group Mandiri. Pengumpulan data dalam penelitian ini menggunakan survei angket, dimana menggunakan sensus atau mengambil seluruh populasi PT. Arum Group Mandiri. Teknik dalam pemilihan responden dilakukan dengan menggunakan snowball sampling, dimana teknik ini dikenal sebagai teknik bola salju yang mengambil sampel awal sebagai informasi untuk menyebutkan data sampel selanjutnya sehingga jumlah sampel terpenuhi [11]. Komponen dalam SNA (social network analysis) dibagi menjadi tiga bagian [10], yaitu yang pertama group (komunitas) atau kelompok yang minimal jumlah anggotanya 25 orang, yang kedua interaction (interaksi antara beberapa aktor atau individu), dan yang ketiga attribute (jenis kelamin, umur, dll). Dalam penelitian ini melibatkan seluruh karyawan PT. Arum Mandiri Group yang berjumlah 43 orang dari tiga divisi.

Langkah selanjutnya adalah dengan mentabulasikan data dari angket dalam matriks atribut (jenis kelamin, jabatan, divisi) dan matriks hubungan (sentralitas) dengan menggunakan format Excel, dimana diberikan nilai 0 apabila tidak terdapat hubungan dan diberikan nilai 1 apabila terdapat hubungan. Hasil data yang sudah ditabulasikan di Excell kemudian dipindahkan dalam software UCINET 6 agar dapat dianalisis [7], [8]. Materi dalam pengisian angket kolaborasi karyawan menggunakan format dua bagian: yang pertama name generator dan bagian kedua name interpreter, dimana bagian pertama menyebutkan aktor yang mempunyai relasional serta bagian kedua memvalidasi data yang disebutkan oleh responden awal [12], [2].

Pemanfaatan Social Network Analysis (SNA) untuk Menganalisis Kolaborasi Karyawan pada PT. Arum Mandiri Group (Dendy Kurniawan) 


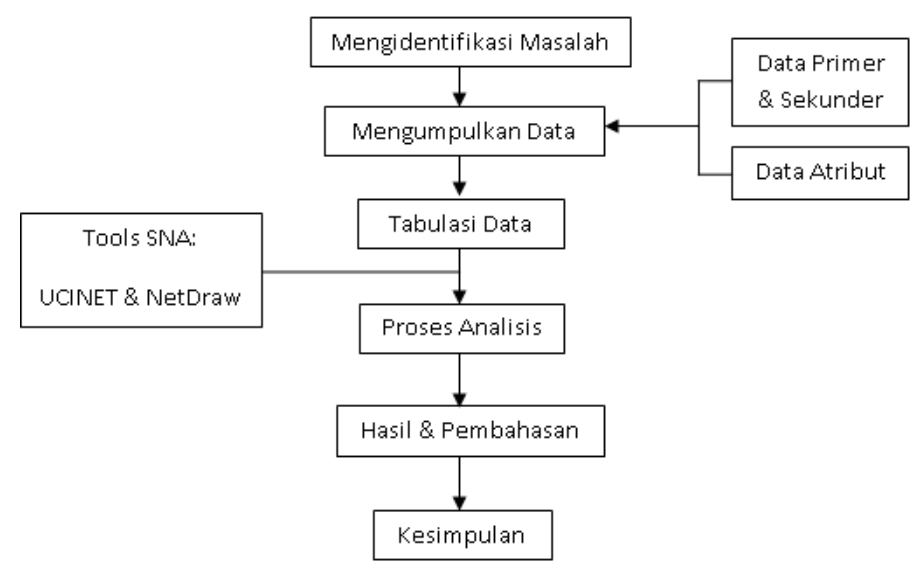

Gambar 1. Tahap Penelitian

\section{b. Level Sistem}

Level sistem adalah gambaran secara menyeluruh tentang jaringan (network) yang lebih menginterpretasikan struktur jaringan dan karakteristik jaringan [12]. Dalam mengukur struktur jaringan dan karakteristik jaringan menggunakan komponen density atau kepadatan jaringan dengan melakukan perbandingan [13].

\section{c. Pengukuran Centrality}

Dalam menguji sebuah hubungan di sebuah organisasi seperti kolaborasi karyawan, SNA diukur melalui tiga tingkatan, yaitu Degree Centrality, Closenness Centrality, dan Betweenness Centrality [14]. Dalam Degree Centrality mencirikan individu yang memiliki tingkat kepopuleran tertinggi dengan indikator nilai indegree dan outdegree yang tinggi [12]. Sedangkan dalam Closenness Centrality mencirikan individu yang memiliki hubungan relasional terpendek atau sederhananya individu yang mempunyai jalur tercepat dalam menyebarkan informasi kepada individu lainnya [12], [13], [14]. Serta Betweenness Centrality mencirikan individu yang memiliki tingkat kemampuan komunikasi relasional yang paling baik, sehingga memungkinkan untuk mengendalikan information control [15].

\section{d. Clique (Klik)}

Klik memiliki definisi sebagai pengumpulan individu (aktor) dengan cara dikelompokkan dalam suatu network dengan memasukkan semua hubungan antar individu yang saling berinteraksi dengan semua anggota komunitasnya [17], [18]. Dalam menentukan jumlah hubungan yang terjadi pada clique (klik) tidak terdapat aturan batasan maksimalnya, tetapi minimal ada tiga hubungan (relasi) yang terjalin antara beberapa individu dengan komunitasnya [12].

\section{e. Graf}

Graf memiliki pengertian network structure yang memiliki fungsi untuk membuat pemodelan hubungan relasional dengan objek seorang individu atau aktor dalam dengan metode SNA, yang disimbolkan dengan bentuknya berupa kumpulan hubungan node yang TRANSFORMATIKA Vol.17, No.2, January 2020: $168-178$ 
terkait sehingga membentuk sebuah sociogram [19]. Dalam sociogram terdapat hubungan yang terarah dengan simbol garis (edge) yang akan membantu dalam memetakan hubungan antar individu dalam komunitas atau organisasi [19].

\section{Hasil dan Pembahasan}

\subsection{Density}

Hasil hitungan dengan menggunakan software UCINET 6 yang terlampir pada Tabel 1 menunjukkan bahwa ada 269 ikatan yang terjadi dalam struktur jaringan. Nilai average pada density dalam struktur jaringan sebesar 14,9\% yang terlihat pada tabel 1, sehingga dapat ditarik kesimpulan ada kemungkinan hubungan antara aktor (individu) lemah karena kurang dari $50 \%$ [12]. Kepadatan jaringan yang lemah dapat diatasi dengan berbagai inovasi yang dilakukan oleh perusahaan seperti lebih meningkatkan intensitas interaksi antara individu dalam beberapa divisi melalui pertemuan yang bersifat formal (meeting) maupun informal (hangout).

Tabel 1. Density

\begin{tabular}{ccc}
\hline \multicolumn{3}{c}{ Density / Average Matrix Value } \\
\hline 1. Density & 2. No. of ties & 3. Avg Degree \\
\hline 0,149 & 269 & 6,256 \\
\hline
\end{tabular}

Sumber: data diolah. 2019

\subsection{Degree Centrality}

Nilai degree centrality dapat dilihat pada tabel 2, dimana terdapat 43 orang dalam jaringan kelompok, tetapi hanya terdapat beberapa aktor (individu) yang mempunya tingkat sentralitas tinggi (tingkat kepopuleran/kesukaan). Dalam tabel 2, aktor Id 31 merupakan aktor laki-laki dari divisi cucian motor dengan jabatan SPV, memiliki nilai centrality paling tinggi dengan nilai lima belas (15 kali) untuk menghubungi dan sepuluh (10 kali) untuk dihubungi. Hal ini memberikan gambaran bahwa aktor Id 31 mengirimkan sebuah informasi kepada 15 orang di dalam jaringan dan menerima informasi dari 10 orang lain dalam kelompoknya. Degree Centraity dapat menjadi rujukan oleh bagian sumber daya manusia (SDM) PT. Arum Mandiri Group untuk menentukan individu-individu yang tepat dalam menduduki posisi penting dalam perusahaan, khususnya didasarkan pada individu yang memiliki tingkat degree centrality tertinggi (tingkat kesukaan yang tinggi).

Tabel 2. Degree Centrality

\begin{tabular}{rrrrr}
\hline \multicolumn{5}{c}{ Freeman's Degree Centrality Measures } \\
\hline ID & OutDegree & InDegree & NrmOutDeg & NrmInDeg \\
\hline 31 & 15.000 & 10.000 & 35.714 & 23.810 \\
42 & 11.000 & 7.000 & 26.190 & 16.667 \\
40 & 10.000 & 5.000 & 23.810 & 7.143 \\
39 & 10.000 & 3.000 & 23.810 & 19.048 \\
16 & 9.000 & 8.000 & 21.429 & 9.524 \\
\hline
\end{tabular}

Sumber: data diolah, 2019

Pemanfaatan Social Network Analysis (SNA) untuk Menganalisis Kolaborasi Karyawan pada PT. Arum Mandiri Group (Dendy Kurniawan) 
Pada gambar 2 diperlihatkan aktor yang memiliki tingkat kepopuleran atau kesukaan tertinggi (degree centrality) pada sociogram, dimana aktor yang dilingkari warna ungu dengan Id 31, 42, 40, 39 (divisi cucian mobil/sepeda motor) dan Id 16 (divisi perumahan) merupakan 5 besar nilai tertinggi degree centrality. Beberapa karyawan divisi cucian menyatakan aktor Id 31 merupakan aktor laki-laki pada divisi cucian motor dengan jabatan SPV dan memiliki masa kerja terlama yaitu 6 tahun serta dianggap sebagai panutan oleh rekan-rekan kerjanya.

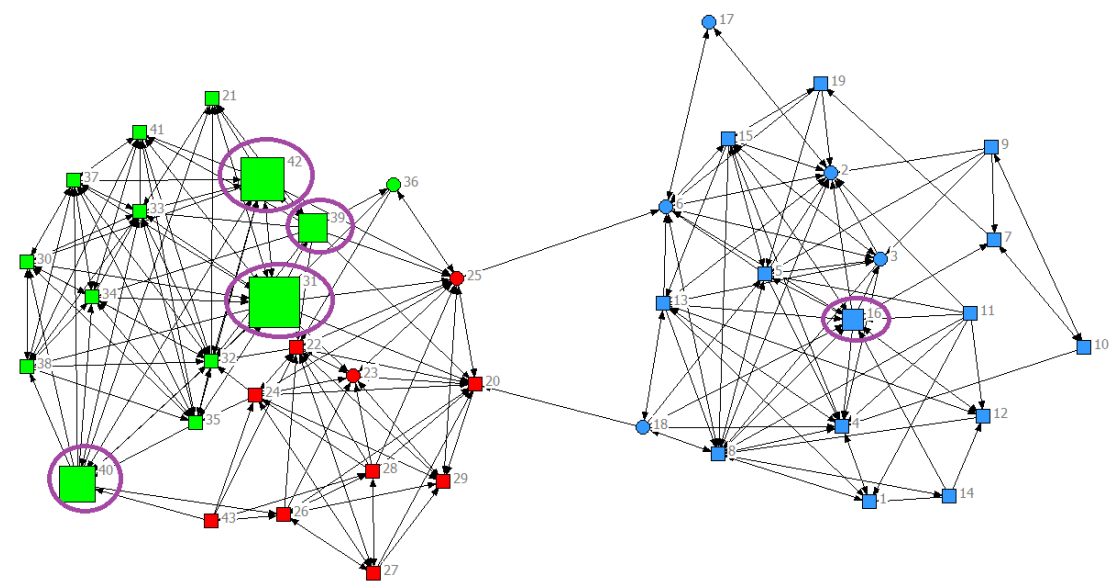

Gambar 2. Sociogram Degree Centrality

\subsection{Closenness Centrality}

Hasil perhitungan pada tabel 3, dimana nilai closeness centrality dari beberapa individu diukur menggunakan komponen: incloseness dan outcloseness untuk menunjukkan kedekatan antara individu dengan kelompok jaringannya. Sehingga berdasarkan perhitungan pada Tabel 3 terlihat individu Id 25 (divisi bengkel sepeda motor) memiliki nilai incloseness dan outcloseness paling tinggi. Individu Id 25 menjadi salah satu individu yang memiliki kedekatan dengan divisi lain dan menjadi kolaborator dengan dua divisi lainnya. Kolaborasi antara individu-individu hanya terkonsentrasi pada divisi bengkel sepeda motor dan divisi perumahan, yaitu pada aktor Id 20, 25, 6, dan 18. Diharapkan kedepan PT. Arum Mandiri Group dapat membuat beberapa terobosan agar bisa tercipta kolaborasi yang baik antar divisi.

Tabel 3. Closeness Centrality

\begin{tabular}{llc}
\hline \multicolumn{3}{c}{ Closeness Centrality } \\
\hline ID & inCloseness & outCloseness \\
\hline 25 & 50.602 & 27.815 \\
6 & 47.191 & 26.752 \\
20 & 46.154 & 25.301 \\
23 & 41.584 & 22.703 \\
22 & 39.252 & 27.273 \\
\hline
\end{tabular}

Sumber: data diolah, 2019

TRANSFORMATIKA Vol.17, No.2, January 2020: 168 -178 
Pada gambar 3 diperlihatkan aktor yang memiliki tingkat kedekatan dengan karyawan tertinggi (closeness centrality) pada sociogram, dimana aktor yang dilingkari warna ungu dengan Id 25, 20, 23, 22 (divisi bengkel sepeda motor) dan Id 6 (divisi perumahan) merupakan 5 besar nilai tertinggi closeness centrality. Beberapa karyawan divisi bengkel motor menyatakan aktor Id 25 merupakan karyawan perempuan bagian front desk di divisi bengkel motor yang dikenal ramah, supel, dan suka menolong oleh rekan-rekan kerjanya. Sedangkan karyawan Id 6 merupakan karyawan perempuan bagian keuangan pada divisi perumahan dengan masa kerja 4 tahun serta memiliki gelar sariana.

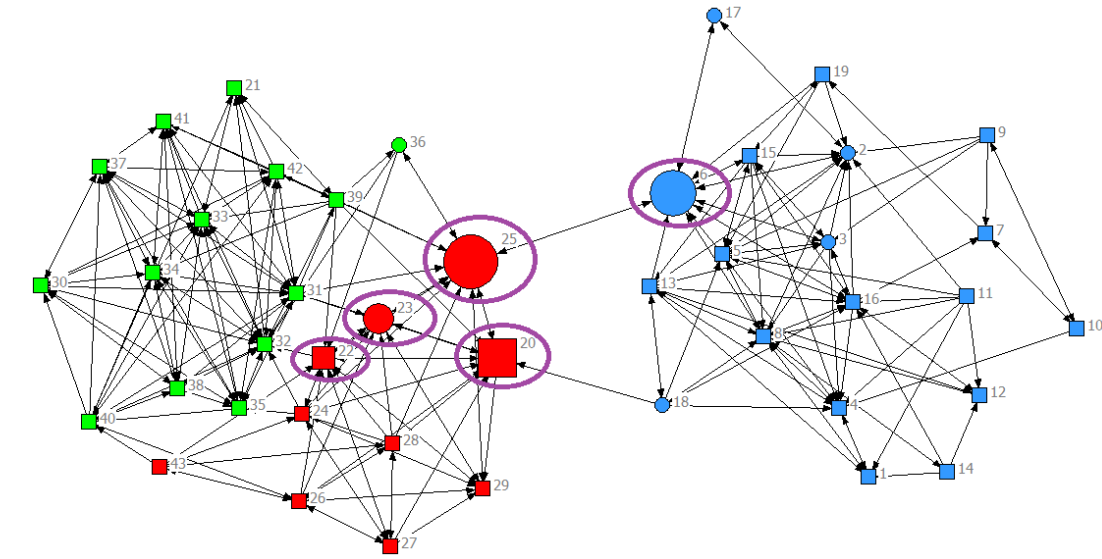

Gambar 3. Sociogram Closeness Centrality

\subsection{Betweenness Centrality}

Pada tabel 4 hasil perhitungan nilai betweenness centrality, di mana aktor perempuaden ngan Id 25 (divisi bengkel sepeda motor) memiliki nilai nBetweenness paling tinggi, dimana memiliki pengertian aktor (individu) memiliki posisi favorit dalam jaringan, karena banyak aktor yang saling bergantung pada mereka agar dapat membuat jaringan pertemanan dengan individu lain. Sedangkan posisi kedua hingga kelima ditempati oleh aktor Id 6 (divisi perumahan), Id 22 (divisi bengkel sepeda motor), dan Id 32 dan 31 (divisi cucian mobil/sepeda motor). Individu dengan nilai betweenness centrality tertinggi melibatkan semua divisi tetapi terpisah dimana divisi cucian mobil/sepeda motor tidak bisa langsung terhubung dengan divisi perumahan. Permasalahan ini terjadi karena tidak ada aktor penghubung sebagai broker pada divisi cucian mobil/sepeda motor dan divisi perumahan, sehingga diharapkan dengan adanya berbagai inovasi dari perusahaan dapat terjadi kolaborasi antara individu-individu tersebut.

Tabel 4. Betweennness Centrality

\begin{tabular}{rcc}
\hline \multicolumn{3}{c}{ Freeman Betweenness Centrality } \\
\hline ID & Betweenness & nBetweenness \\
\hline 25 & 743.194 & 43.159 \\
6 & 739.020 & 42.916 \\
32 & 303.025 & 17.597 \\
22 & 286.640 & 16.646 \\
31 & 223.722 & 12.992 \\
\hline
\end{tabular}

Sumber: data diolah, 2019

Pemanfaatan Social Network Analysis (SNA) untuk Menganalisis Kolaborasi Karyawan pada PT. Arum Mandiri Group (Dendy Kurniawan) 
Pada gambar 3 diperlihatkan aktor yang menjadi favorit dalam menyelesaikan atau memberikan saran kepada karyawan lain dengan nilai betweenness centrality tertinggi pada sociogram, dimana aktor yang dilingkari warna ungu dengan Id $25 \mathrm{dn} 22$ (divisi bengkel motor), Id 6 (divisi perumahan), dan Id 32 dan 31 (divisi cucian motor) merupakan 5 besar nilai tertinggi betweenness centrality. Beberapa karyawan divisi bengkel motor menyatakan aktor Id 25 merupakan front desk di divisi bengkel motor yang dikenal ramah, supel, dan suka menolong oleh rekan-rekan kerjanya. Aktor Id 25 merupakan lulusan sarjana dengan masa kerja 3 tahun, sehingga dianggap sebagai panutan dan referensi dalam problematika pekerjaan oleh rekan-rekan kerjanya.

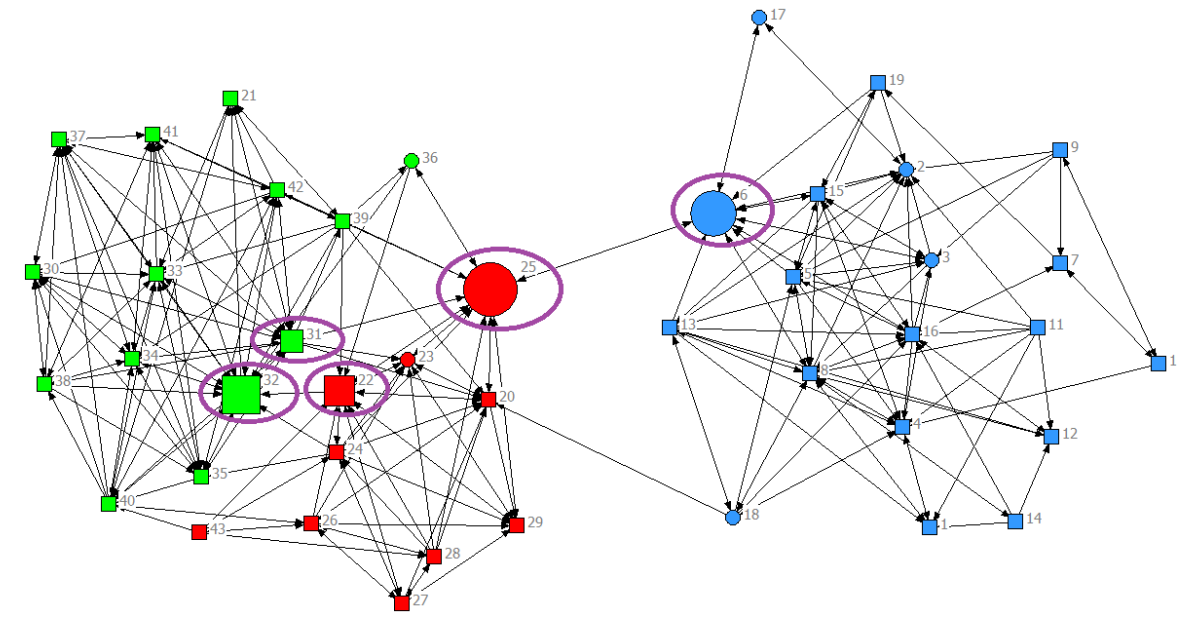

Gambar 4. Sociogram Betweenness Centrality

\subsection{Clique}

Hasil dari kuesioner dapat dihasilkan sampai 5 clique dengan batasan minimal 4 jumlah anggota seperti yang ditunjukkan pada tabel 5 yang menunjukkan dimana clique hanya menampung 4 sampai dengan 6 aktor dari 43 aktor di dalam struktur jaringan. Dalam pola clique didominasi oleh aktor yang berasal dari divisi cucian motor serta memiliki range umur yang sama anatara umur 29 s/d 32 tahun. Adanya clique dalam organisasi memiliki dampak positif dan juga negatif. Clique memiliki dampak positif apabila hubungan tersebut tidak memiliki conflict of interest serta dapat meningkatkan kolaborasi secara efektif antar divisi. Sedangkan clique memiliki dampak negatif apabila clique dipandang hanya kumpulan anggota individu yang hanya membuat sebuah geng/faksi yang sifatnya destruktif dan resistensi terhadap perubahan organisasi yang sifatnya konstruktif.

Tabel 5. Clique

\begin{tabular}{cc}
\hline Clique & \multicolumn{1}{c}{ Actor } \\
\hline I & $30,31,32,33,35,37$ \\
II & $31,32,33,35,37,42$ \\
III & $30,31,32,34,35,37$ \\
IV & $31,34,35,37,41$ \\
V & $31,33,40,42$ \\
\hline
\end{tabular}

Sumber: data diolah. 2019

TRANSFORMATIKA Vol.17, No.2, January 2020: 168 - 178 


\subsection{Sociogram}

Pola hubungan diantara node yang didasarkan pada atribut divisi, jenis kelamin, jabatan dari masing-masing individu dijabarkan dalam tabel 6, 7 dan 8 serta gambar 2. Warna dibedakan berdasarkan divisi atau bagian, warna biru untuk divisi perumahan, warna hijau untuk divisi cuci motor, dan warna merah untuk divisi bengkel. Sedangkan untuk jenis kelamin wanita memakai simbol circle dan jenis kelamin pria memakai simbol square. Ukuran simbol dibedakan menjadi dua, simbol besar (large) untuk SPV dan manajer, sedangkan untuk simbol kecil (small) untuk karyawan staf.

Tabel 6. Divisi, Simbol, dan ID Aktor

\begin{tabular}{lll}
\hline Bagian & Warna & \multicolumn{1}{c}{ Id Aktor } \\
\hline Perumahan & biru & $1,2,3,4,5,6,7,8,9,10,11$, \\
& & $12,13,14,15,16,17,18,19$ \\
Cucian & hijau & $21,30,31,32,33,34,35,36$, \\
& & $37,38,39,40,41,42$ \\
Bengkel & merah & $20,22,23,24,25,26,27,28$, \\
& & 29,43 \\
\hline
\end{tabular}

Sumber: data diolah. 2019

Tabel 7. Simbol dan Jenis Kelamin

\begin{tabular}{ccc}
\hline No & Jenis Kelamin & Simbol \\
\hline 1 & Pria & Square \\
2 & Wanita & Circle \\
\hline
\end{tabular}

Sumber: data diolah 2019

Tabel 8. Simbol dan Jabatan

\begin{tabular}{ccc}
\hline Group & Gender & Size \\
\hline 1 & SPV & Large \\
2 & Staff & Small
\end{tabular}

Sumber: data diolah 2019

Sociogram gambar 5 lebih didominasi secara kuantitas oleh individu pria, akan tetapi di pusat jaringan lebih didominasi individu wanita (Id 25). Pada gambar 2 terlihat karyawan level SPV paling sering melakukan kolaborasi dengan karyawan level staf adalah individu 16, 20, dan 31. Sedangkan indivdu yang mempunyai perbedaan hubungan relasional dengan struktur organisasi formal, yaitu individu 18 dan 25. Pada gambar 5 terlihat hanya dua divisi yang individunya memiliki kolaborasi yaitu divisi bengkel sepeda motor (warna merah) dengan divisi perumahan (warna biru) serta hanya diwakili oleh 4 aktor saja (Id 25, 20, 6, 18). Dalam sociogram menggambarkan interaksi dalam perusahaan mengelompok hanya pada divisinya masing-masing, sehingga kolaborasi antar divisi belum terlihat secara optimal. Diharapkan 
dengan adanya pertemuan rutin yang dirancang secara inovatif dapat lebih mempererat kolaborasi antara individu atau karyawan PT. Arum Mandiri Group.

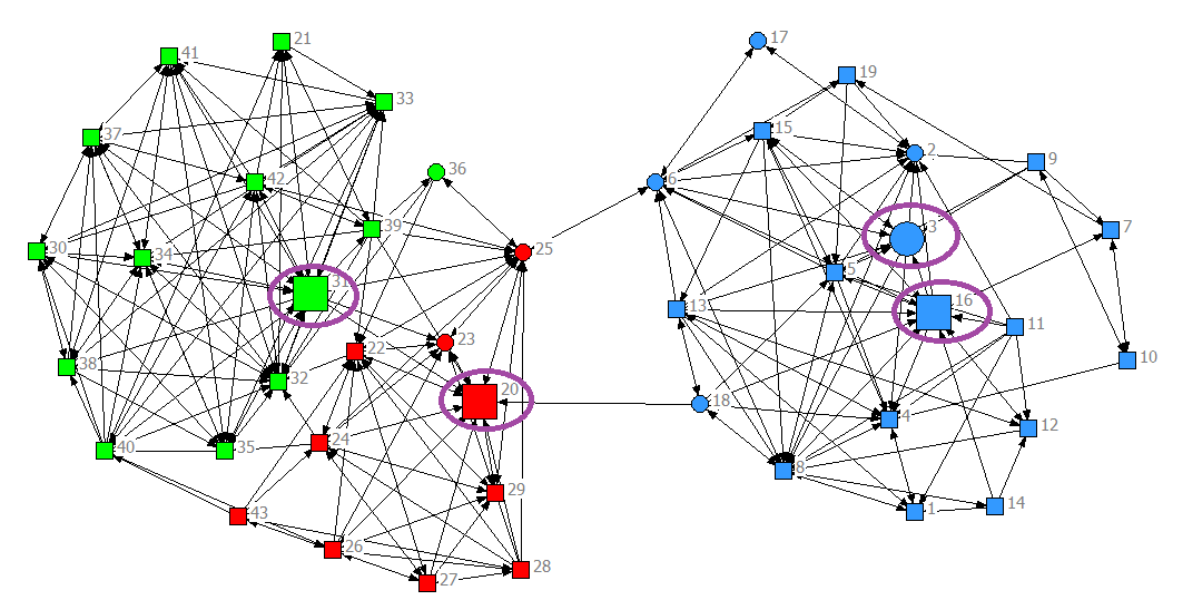

Gambar 5. Sociogram Berdasarkan Divisi

\section{Kesimpulan \& Saran}

Penggunaan metode SNA menunjukkan hasil penelitian menunjukkan ikatan yang lemah dengan indikator nilai density 14,9\% (tingkat kepadatan jaringan kurang dari 50\%). Aktor (node) yang memiliki nilai degree centrality (sering dihubungi) merupakan aktor 31 bagian SPV cucian (karyawan senior). Sedangkan aktor (node) yang memiliki nilai closeness centrality (dapat menjangkau secara dekat) dan betweenness centrality (penghubung yang baik) tertinggi merupakan aktor 25 bagian front desk bengkel. Dalam hal pengelompokkan aktor (clique) yang menggunakan batasan minimal 4 anggota dan diperoleh terdapat 5 clique. Pola interaksi hubungan dalam organisasi mengelompok pada bagian atau divisi masing-masing, sedangkan hanya beberapa aktor yang berinteraksi tidak sesuai divisi. Berdasarkan hasil penelitian ini dapat menjadi saran kebijakan bagi perusahaan dalam menempatkan karyawan yang memiliki pola interaksi yang bagus agar dapat dipromosikan menjadi calon pemimpin atau leader dimasa yang akan datang. Peneliti berharap hasil dari penelitian ini bisa diteliti lebih lanjut untuk menganalisis pola hubungan interaksi yang lebih luas.

Solusi yang bisa dilakukan oleh perusahaan untuk meningkatkan kolaborasi dalam organisasi dapat melalui diskusi melaui pertemuan rutin (meeting) yang bisa dilakukan secara terprogram maupun tidak terpogram agar bisa melakukan perencanaan serta evaluasi dari beberapa divisi terkait kinerja karyawan dan kendala yang dihadapi dalam permasalahan teknis serta non teknis, sehingga tercipta komunikasi dua arah yang dapat meningkatkan kolaborasi dalam organisasi PT. AMI. Program refreshing seperti kegiatan outbound dengan membagi beberapa tim dari unsur berbagai divisi dapat meningkatkan kedekatan emosi yang berdampak pada kolaborasi dalam bidang pekerjaan. Selain itu dapat pula para SPV mengagendakan pertemuan yang sifatnya informal seperti mengadakan acara makan-makan atau hangout diluar jam kerja untuk semakin mengakrabkan semua karyawan dari berbagai divisi, sehingga diharapkan kolaborasi antara berbagai divisi bisa lebih terjalin erat.

TRANSFORMATIKA Vol.17, No.2, January 2020: $168-178$ 


\section{Referensi}

[1] N. A. Siregar and Z. Ritonga, "The Analysis of Human Capital and Social Capital on Company Performance,” J. Online Jar. Pengaj. Seni Bina, vol. 14, pp. 139-143, 2019.

[2] E. Zusrony, H. D. Purnomo, S. Yulianto, and J. Prasetyo, "Analisis Pemetaan Jaringan Komunikasi Karyawan Menggunakan Social Network Analysis Pada Perusahaan Multifinance," INTENSIF J. Ilm. Penelit. dan Penerapan Teknol. Sist. Inf., vol. 3, no. 2, pp. 145-158, 2019.

[3] R. Sidik, P. S. Informasi, and U. K. Indonesia, "Model Sistem Informasi Kolaborasi Pada Kerjasama Antar Universitas (University To University)," J. Teknol. dan Inf., vol. 4, no. 2, pp. 1-10, 2014.

[4] J. V. Manopo, "Peran Komunikasi Organisasi Dalam Membentuk Efektivitas Kerja Karyawan CV Magnum Sign and Print Advertising Samarinda," eJournal lmu Komun., vol. 2, no. 3, pp. 357-372, 2014.

[5] A. P. Wardhani, H. Leonardo Budi, and M. Maria Magdalena, "Pengaruh Lingkungan Kerja, Komunikasi dan Kepemimpinan Terhadap Kinerja Pegawai," J. Manage., vol. 2, no. 1, pp. 344-354, 2016.

[6] M. Pengestu, "Jaringan Komunikasi di The Piano Institute Surabaya," E- Komunikasi, Univ. Kristen Petra Surabaya, vol. 3, pp. 1-12, 2015.

[7] Y. Wu and Z. Duan, "Social network analysis of international scientific collaboration on psychiatry research," Int. J. Ment. Health Syst., vol. 9, no. 1, 2015.

[8] A. Syarifudin et al., "PEMETAAN REKANAN PADA JARINGAN SISTEM PENGADAAN SECARA ELEKTRONIK ( SPSE ) DENGAN SOCIAL NETWORK ANALYSIS ( SNA )," in Seminar Nasional Informatika 2018, 2018, pp. 43-50.

[9] H. Tuhuteru and A. Iriani, "Analisis Kolaborasi Penelitian Ilmiah Dosen Fakultas X dengan Social Network Analysis (SNA) Jurnal Teknik Informatika dan Sistem Informasi," J. Tek. Inform. dan Sist. Inf., vol. 4, no. No. 1, pp. 149-158, 2017.

[10] B. E. Giri, D. Manongga, and A. Iriani, "Using Social Networking Analysis (SNA) to Analyze Collaboration between Students (Case Study: Students of Open University in Kupang)," Int. J. Comput. Appl., vol. 85, no. No. 1, pp. 44-49, 2014.

[11] I. Etikan, "Comparision of Snowball Sampling and Sequential Sampling Technique," Biometrics Biostat. Int. J., vol. 3, no. 1, 2017.

[12] Eriyanto, Analisis Jaringan Komunikasi, Edisi 1. Jakarta: Kencana, 2014.

[13] T. W. Valente, Social Networks and Health: Models, Methods, and Applications. 2010.

[14] C. Prell, "Becoming Familiar with Social Networks," in Social Network Analysis: History, Theory and Methodology, 2012, pp. 7-18.

[15] M. T. Anwar, A. Iriani, and D. H. F. Manongga, "Analisis Pola Persebaran Pornografi pada Media Sosial dengan Social Network Analysis," Buana Inform., vol. 9, no. 1, pp. 4352, 2018.

[16] Q. Luo and D. Zhong, "Using social network analysis to explain communication characteristics of travel-related electronic word-of-mouth on social networking sites," Tour. Manag., vol. 46, pp. 274-282, 2015.

[17] S. P. Borgatti, M. G. Everett, and J. C. Johnson, "10 Centrality BT - Analyzing Social Networks," in Analyzing Social Networks, 2013, p. 304.

[18] S. P. Borgatti, M. G. Everett, and J. C. Johnson, Analyzing Social Networks, 2nd Editio. London: SAGE Publication Ltd, 2018.

[19] F. N. Maulidya, W. Witanti, and A. I. Hadiana, "Pembangunan Sistem Informasi Pola Hubungan Kerja Antar Tenaga Medis Pada Rumah Sakit Jiwa Provinsi XYZ Menggunakan Social Network Analysis," in Prosiding Seminar Nasional Sains dan Teknologi ke-9, 2018, pp. 214-219. 